\title{
IDENTIFICATION OF THE POLISH STRAINS OF CHALARA OVOIDEA USING RAPD MOLECULAR MARKERS
}

\author{
WOJCIECH KRAJ ${ }^{1}$, TADEUSZ KOWALSKI ${ }^{2}$ \\ ${ }^{1}$ Department of Forest Tree Physiology \\ 2 Department of Forest Pathology \\ Agricultural University \\ 29 Listopada 46, 31-425 Kraków, Poland \\ e-mail: rltkowal@cyf-kr.edu.pl
}

(Received: March 23, 2004. Accepted: May 21, 2004)

\begin{abstract}
On the basis of morphological features and RAPD markers the strains of Chalara ovoidea found in Poland on planks and on stems of beech trees were identified. As reference strains the cultures taken from CBS Utrecht were employed; they were cultures CBS 354.76 and CBS 136.88. The amplification of genomic DNA was conducted using 10 primers (OPA01-OPA10), 7 of which (OPA01-OPA05, OPA09, OPA10) gave positive results. In total 42 fragment of DNA (bands) were obtained. In case of primers OPA03, OPA04, OPA05, and OPA09 all obtained fragments for analyzed strains were fully monomorphic. This means, that no genetic variability was found using the above mentioned primers. Low genetic variability was ascertained in the analysis of frequency of occurrence of DNA fragments using other primers, namely OPA01, OPA02, and OPA10.

The matrix and dendrogram of genetic affinities among different strains of Chalara, calculated using the Jaccard's similarity coefficient suggested, that the most similar strains are the ones coming from Poland (HMIPC 16136 and HMIPC16664) as well as the strain CBS 136.88, while somewhat different from them is the strain CBS 354.76. To determine, how exactly did the dendrogram reflect genetic affinity among analyzed strains, the Mantel's test was employed. The correlation coefficient amounted to 0.78 , suggesting that the strains under study had been grouped properly. The results showed, that the fungal strains found in southern Poland represent the species Chalara ovoidea.
\end{abstract}

KEY WORDS: Chalara ovoidea, Fagus sylvatica, RAPD, genetic variation.

\section{INTRODUCTION}

Chalara ovoidea Nag Raj \& Kendrick is the hyphomycete fungus which was described as a new species quite recently (Nag Raj and Kendrick 1975). It occurs predominantly on trees from the genus Fagus, less commonly on Quercus. Morphologically it is very similar to Chalara thielavioides (Peyr.) Nag Raj \& Kendrick, which was found on Juglans and on Ulmus (Nag Raj and Kendrick 1975; Paulin-Mahady et al. 2002). Chalara ovoidea has not been recorded yet from Poland. Only recently it was found on discolored beech planks, as well as on live beech trees showing symptoms of decline (T. Kowalski, unpublished).

The isolated cultures displayed several physiological and developmental features different from those described in the literature (Nag Raj and Kendrick 1975; Paulin and Harrington 2000). Among the most important of them is the development of teleomorph, which - according to the literature - has not been observed earlier (Nag Raj and Kendrick 1975; Paulin-Mahady et al. 2002). To proceed with the studies, it was necessary to be certain if the preliminary identification of the species collected in Poland was correct. Two cultures from CBS Utrecht (Netherlands) were used to make comparisons. The unequivocal identification of colonies on the basis of their morphological features is difficult, because there is a high variability in morphology and a big variability in sizes of conidia, especially their lengths, as well as in the size of aleuriospores and the frequency of their occurrence. Therefore RAPD analysis of molecular markers (Williams et al. 1990) was employed to determine, if the Polish and the CBS Utrecht strains belong to the same species.

\section{MATERIAL AND METHODS}

In the study 4 strains of Chalara ovoidea were used:

HMIPC 16136 - isolated on June 20, 1995 by T. Kowalski, representing colonies isolated from beech $(F$. sylvati$c a$ ) planks stored in wood processing factory in Wadowice 
(southern Poland), showing symptoms of gray-brown discoloration

HMIPC 16664 - isolated on January 18, 2000 by T. Kowalski, represents colonies isolated from exposed wood in place of necroses of stems of European beech ( F. sylvatica) in the Nawojowa Forest District (southern Poland)

CBS 354.76 - obtained from the Centraalbureau voor SchimmelCultures, Netherlands, isolated from firewood (Paulin-Mahady et al. 2002).

CBS 136.88 - obtained from the Centraalbureau voor SchimmelCultures, Netherlands, isolated from Quercus (Paulin-Mahady et al. 2002).

\section{Morphological examination}

For the morphological examination colonies were cultivated on $2 \%$ malt extract agar (MEA, Difco). Description of the structure of a colony and measurements of spores were done on 3-week old cultures, incubated at the temperature of $20^{\circ} \mathrm{C}$ without light. For each culture 30 endoconidia and 30 aleuriospores submerged in water were measured using a Zeiss microscope with a $100 \times$ Planapo objective with interference differential contrast.

\section{Extraction of DNA and RAPD analysis}

The genomic DNA was obtained from the cultures of Chalara ovoidea growing on malt extract agar in Petri dishes. Extraction of DNA was carried out using a modified method developed by Carlson and others (1991). The aerial hyphae was collected from the surface of the medium, put into a mortar and powdered with $1000 \mu \mathrm{l}$ of Carlson Lysis Buffer (100 mM Tris pH 9.5, 20 mM EDTA, $1.4 \mathrm{M} \mathrm{NaCl}$, $2 \%$ CTAB, $1 \%$ PEG 8000, 0.2\% 2-mercaptoethanol) at the temperature of $65^{\circ} \mathrm{C}$. The powdered hyphae was put into $1.5 \mathrm{ml}$ Eppendorf test-tubes and then incubated at the temperature of $65^{\circ} \mathrm{C}$ for 1 hour. Every 15 minutes the content of incubated test-tubes was being mixed.

Then the samples were centrifuged $(10000 \mathrm{rpm}$ for 10 minutes) at the temperature of $4^{\circ} \mathrm{C}$. The water phase was put to the next test-tube and $500 \mu \mathrm{l}$ of a chloroform and isoamyl alcohol mixture 24:1 was added. After mixing the samples were centrifuged (13 $000 \mathrm{rpm}$ for 10 minutes). The water phase was collected to a test-tube and $400 \mu \mathrm{l}$ of cooled isopropanol was added in order to precipitate the nucleic acids. This process was conducted at the temperature of $-20^{\circ} \mathrm{C}$ for a dozen hours. Then the samples were centrifuged (13 $000 \mathrm{rpm}$ for 10 minutes) and the supernatant was collected. The pellet of DNA was rinsed with ethyl alcohol and dried at ambient temperature. Nucleic acids were diluted in $30 \mu \mathrm{l}$ of TE buffer $(10 \mathrm{mM}$ Tris $\mathrm{pH}$ 8.0, $1 \mathrm{mM}$ EDTA) with addition of RNA-se (Sigma) of a concentration of $10 \mu \mathrm{g} / \mathrm{ml}$. Test-tubes were then put for 24 hours in an incubator at the temperature of $37^{\circ} \mathrm{C}$ to permit the RNA-se to operate. The concentration of DNA was determined using a spectrophotometer. Test-tubes with extracted DNA were kept at the temperature of $-20^{\circ} \mathrm{C}$ until next analyses.

For amplification 10 primers OPA01 (Operon) (Table 2) were used. The reaction was conducted employing the genomic DNA extracted from the hyphae of 4 cultures for each of the analyzed strains of Chalara ovoidea. DNA was kept in sterile $0.2 \mathrm{ml}$ Eppendorf's test tubes in $25 \mu \mathrm{l}$ of reaction mixture containing PCR buffer $(750 \mathrm{mM}$ Tris- $\mathrm{HCl}$ (pH 8.8), $200 \mathrm{mM}\left(\mathrm{NH}_{4}\right)_{2} \mathrm{SO}_{4}, 0.1 \%$ Tween 20) (Fermentas), $\mathrm{MgCl}_{2}$ in concentration determined in a previous experiment, $150 \mathrm{mM}$ of a mixture of dNTP (Fermentas), 5 $\mathrm{pM}$ of a primer (Operon) $10 \mathrm{ng}$ of genomic DNA, $3 \mathrm{U}$ Taq DNA polymerase (Fermentas).

Amplification of DNA was conducted in a thermocycler T3 (Biomertra) programmed in a following way: initial denaturation, $94^{\circ} \mathrm{C}, 3$ minutes, then 40 cycles containing the following stages: denaturation, $94^{\circ} \mathrm{C}, 1$ minute, annealing, $36^{\circ} \mathrm{C}, 1$ minute, elongation, $72^{\circ} \mathrm{C}, 2$ minutes. The elongation in the last cycle was prolonged to 5 minutes. The testtubes were cooled down to $4^{\circ} \mathrm{C}$.

For each sample of DNA the amplification was conducted twice to evaluate the repeatability of the results and to

TABLE 1. Dimensions of endoconidia and aleurioconidia in analyzed strains of Chalara ovoidea.

\begin{tabular}{lccc}
\hline \multirow{2}{*}{ Strain } & \multicolumn{2}{c}{ Endoconidia (length $\times$ width) } & \multicolumn{2}{c}{ Aleurioconidia (length $\times$ width) } \\
\cline { 2 - 4 } & range & mean & range \\
\hline HMIPC 16136 & $6.0-32.0 \times 2.8-5.0$ & $14.8 \times 3.7$ & $10.8 \times 8.4$ \\
HMIPC 16664 & $9.0-34.0 \times 2.2-4.2$ & $16.7 \times 3.5$ & $9.0-12.0 \times 7.0-9.0$ \\
CBS 354.76 & $5.0-29.0 \times 2.2-3.5$ & $13.3 \times 2.9$ & $7.0-10.0 \times 8.0-11.0$ \\
CBS 136.88 & $6.0-53.0 \times 2.8-5.0$ & $17.7 \times 3.3$ & $10.0-13.5 \times 7.0-8.0$ \\
& & & $12.0 \times 6.5$ \\
\hline
\end{tabular}

TABLE 2. Primers used for amplification, optimum concentration of Magnesium ions, and range of sizes of obtained products.

\begin{tabular}{|c|c|c|c|c|}
\hline \multirow{2}{*}{ Name of primer } & \multirow{2}{*}{ The sequence of primer } & \multirow{2}{*}{$\begin{array}{l}\text { The optimum } \\
\text { concentration of } \mathrm{Mg}^{2+}[\mathrm{mM}]\end{array}$} & \multicolumn{2}{|c|}{ Sizes of obtained products of amplification (bp) } \\
\hline & & & Minimum & Maximum \\
\hline OPA01 & CAGGCCCTTC & 1.5 & 395 & 2399 \\
\hline OPA02 & TGCCGAGCTG & 2.0 & 561 & 2513 \\
\hline OPA03 & AGTCAGCCAC & 2.0 & 600 & 1297 \\
\hline OPA04 & AATCGGGCTG & 2.0 & 525 & 2244 \\
\hline OPA05 & AGGGGTCTTG & 2.0 & 500 & 2166 \\
\hline OPA06 & GGTCCCTGAC & $\mathrm{X}$ & $\mathrm{X}$ & $\mathrm{X}$ \\
\hline OPA07 & GAAACGGGTG & $X$ & $X$ & $\mathrm{X}$ \\
\hline OPA08 & GTGACGTAGG & $\mathrm{X}$ & $\mathrm{X}$ & X \\
\hline OPA09 & GGGTAACGCC & 1.5 & 509 & 1063 \\
\hline OPA 10 & GTGATCGCAG & 1.5 & 768 & 2287 \\
\hline
\end{tabular}

$\mathrm{X}$ - negative reaction, lack of bands at the concentration of $\mathrm{Mg}^{2+}$ in range $1.0-2.0 \mathrm{mM}$ 
eliminate mistakes. As a negative control the reaction mixture without template DNA was employed.

To identify the products of amplification the electrophoresis was conducted in 2\% agarose gel (Sigma) suspended in a TBE buffer $(89 \mathrm{mM}$ Tris, $89 \mathrm{mM}$ boric acid, $2.5 \mathrm{mM}$ EDTA) (ICN Biomedicals). $0.5 \mu \mathrm{g} / \mathrm{ml}$ of ethidium bromide was added to the gel in order to make the bands visible. For the electrophoresis $8 \mu \mathrm{l}$ of a reaction mixture with loading buffer $(0.25 \%$ bromophenol blue, $0.25 \%$ xylene cyanol FF, 30\% glycerol) was used. A GeneRuler 100 bp Ladder Plus (Fermentas) was used as a marker of the length of DNA fragments. The electrophoresis was conducted at the voltage of $60 \mathrm{~V}$ for 2-3 hours, and then the image of electrophoresis was produced employing a documentation set of electrophoretic gels by Vilber Laurmat.

\section{Optimization of concentration of Magnesium ions} in reaction mixture

To determine the appropriate concentration of the $\mathrm{Mg}^{++}$ ions during the amplification of DNA a series of preliminary experiments was conducted. DNA from one culture was chosen by random for each fungal strain and the PCR reaction was carried out according to the procedure described above. For particular primers three concentrations of Magnesium ions were used: 1.0, 1.5 and $2.0 \mathrm{mM}$. As a negative control a mixture without the template DNA was applied. Then the electrophoresis was conducted and a picture of gels in UV light was made. The most appropriate concentrations of Magnesium ions were chosen on the basis of the number and sharpness (clarity) of the obtained bands. As an excessive concentration of Magnesium the one producing streaks without visible bands or with very poorly visible ones. The too low concentration of $\mathrm{Mg}^{++}$ions was the one that produced low number of poorly visible bands.

\section{Investigation of genetic stability within strains}

To make sure that the analyzed cultures of Chalara ovoidea were genetically stable within strain and were not infected by other microorganisms, from two chosen strains of Chalara (HMIPC 16664 and CBS 354.76) 10 colonies per each strain were brought. The DNA was then extracted from those colonies and amplified using two primers:
OPA02 and OPA03. On the basis of the electrophoretic picture of the separated fragments of DNA (degree of monomorphity of bands) conclusions about the genetic stability of cultures were drawn.

\section{Data analysis}

The length of the electrophoretically separeted fragments of DNA was determined using the BIO-1d ++ software produced by Vilber Laurmat. To each band one of two features was ascribed: 1 - present, or 0 - absent. It was assumed, that the band is monomorphic (strains were genetically identical), if it occurs in all analyzed cultures. Then, using the RAPDistance ver. 1.04 software, a matrix of genetic similarity (calculated employing the Jaccard's similarity coefficient - Jackson et al. 1989; Gower 1985) was constructed:

$$
\frac{n 11}{n-n 00}
$$

where:

$\mathrm{n}$ - number of bands obtained for compared genotypes,

n11 - number of cases, in which the bands occur in both compared genotypes,

n00 - number of cases, in which the bands did not occur in both compared genotypes.

On the basis of the matrix of genetic similarity a cluster analysis was conducted, employing the unweighted pair group average (UPGMA) method. The results were presented graphically in a form of a dendrogram. To estimate, how exactly did the dendrogram represent the genetic distance between analyzed strains of Chalara ovoidea, a Mantel matrix-correspondence test (Mantel 1967) was carried out using the Mantel-Stuct 1.0 software. Basic statistics (mean value, maximum and minimum values, standard deviation, coefficient of variation) were calculated for each strain.

\section{RESULTS}

Colonies of Chalara ovoidea (HMIPC 16136, HMIPC 16664, CBS 136.88, CBS 354.76) were in most cases effuse, with poorly developed aerial mycelium, bright-gray, to dark gray or black (Fig. 1). The structure of some colonies

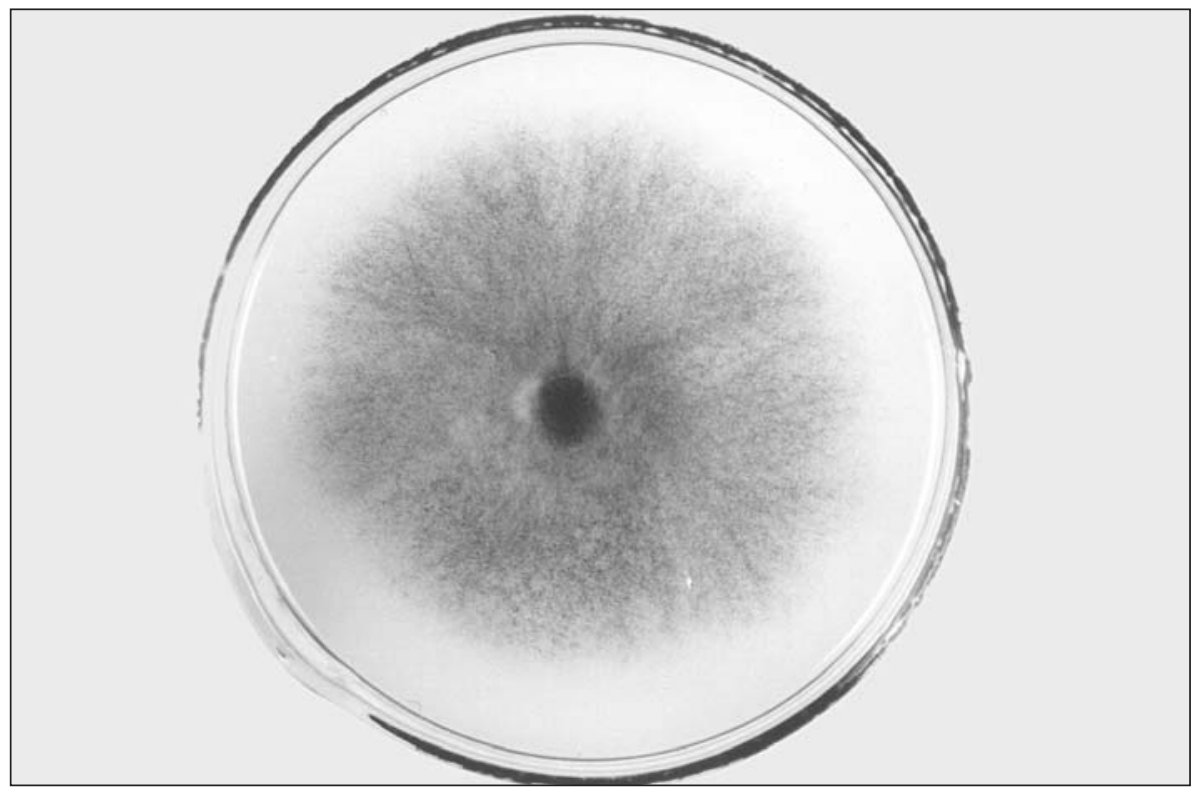

Fig. 1. A colony of Chalara ovoidea HMIPC 16136 (21 days, $\left.21^{\circ} \mathrm{C}, \mathrm{MEA}\right)$. 

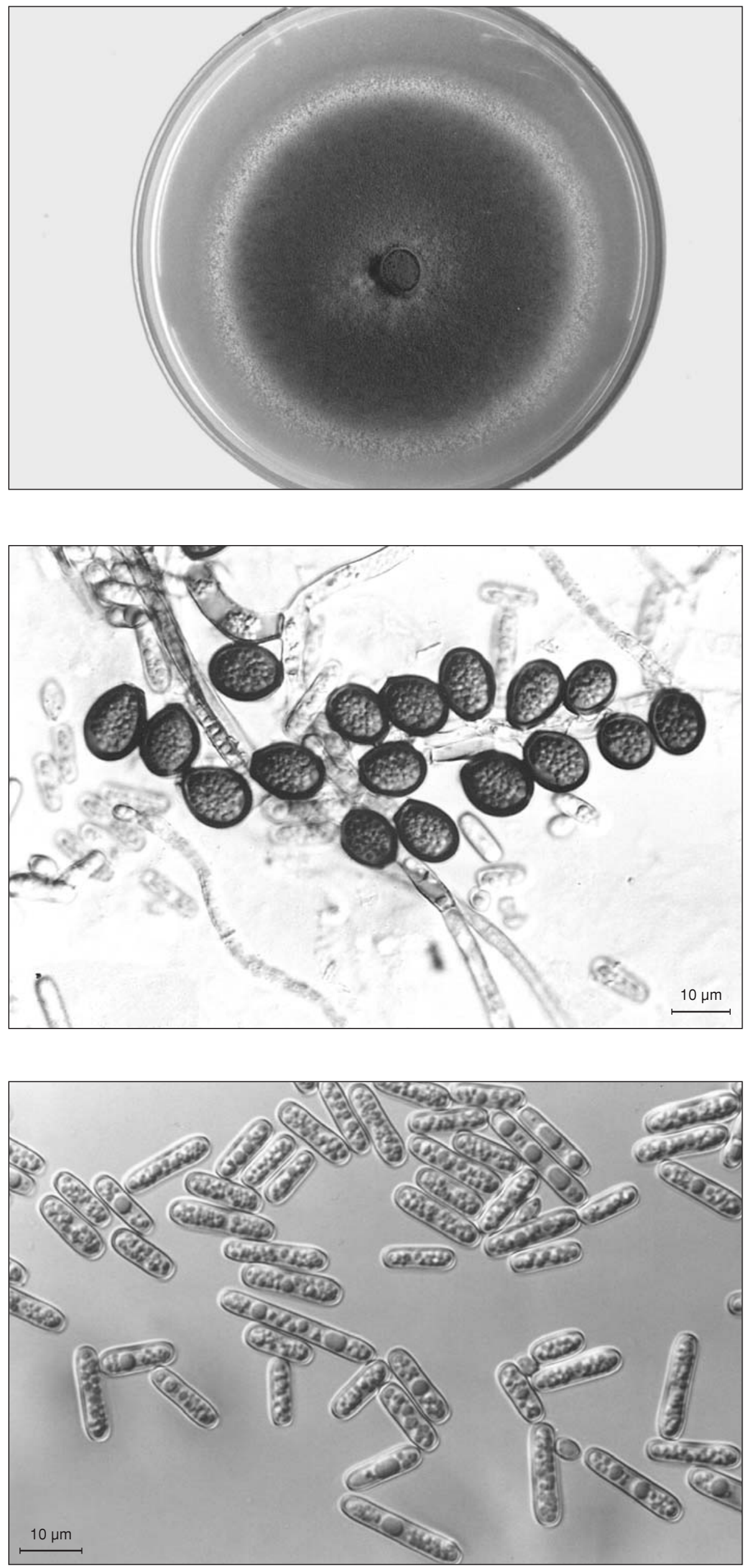

Fig. 2. A colony of Chalara ovoidea CBS 354.76 (21 days, $\left.21^{\circ} \mathrm{C}, \mathrm{MEA}\right)$

Fig. 3. Aleuriospores of Chalara ovoidea HMIPC 16136 produced in a culture growing on MEA.

Fig. 4. Phialoconidia of Chalara ovoidea HMIPC 16136 produced in a culture growing on MEA. 
was more compact, wool-like, only at the outskirts it was powder-like (Fig. 2). In all colonies aleuriospores and endoconidia were produced. The frequency of occurrence of each of those types of spores affected the structure and color of the colony. The occurrence of endoconidia in high numbers resulted in the appearance of a white-gray delicate loose powder. Production of numerous aleuriospores caused made the colony more compact and darkening of its color. The features of the spores were as follows: aleuriospores - single cells, brown, subglobose or pyriform with truncate base (Fig. 3). In the strain HMIPC 16664 the aleuriospores were less numerous, while in the strain CBS 354.76 they attained slightly smaller dimensions than in three other strains (Table 1). Endoconidia (phialoconidia) were single cells, cylindric in shape, hyaline, golden to bright brown color (Fig. 4). In the strain CBS 354.76 the endoconidia - like aleuriospores - were slightly smaller than in other strains (Table 1).

\section{Optimization of concentration of Magnesium ions in reaction mixture}

On the basis of the number of bands, their sharpness and intensity the optimum concentration of Magnesium ions was determined. This concentration was then applied in the analyzes. The optimum concentration of $\mathrm{Mg}^{++}$for particular primers was presented in Table 2.

The results allow to say, that for the primers used in the experiment it is quite easy to match appropriate concentrations of Magnesium ions, allowing for obtaining clearly visible bands, easy for further analyses.

\section{Investigation of genetic stability within strains}

The electrophoretic pictures of DNA fragments obtained for strains HMIPC 16664 and CBS 354.76 were identical for all cultures within strain with the one exception. It suggests almost full genetic stability within strains. On the ba- sis of those results, in order to enhance the credibility of the main experiment, the DNA coming from 4 cultures was used for each strain.

\section{Identification of Chalara ovoidea strains}

For amplification there were chosen the primers, which had given positive PCR reaction at optimization of the concentration of Magnesium ions: these primers were: OPA01 to OPA05, OPA09 and OPA10. As a result of amplification we obtained for 7 above mentioned primers in total 42 fragments of DNA (bands). Chosen pictures of electrophoretic gels were given in Figure 5 and 6. The range of lengths of DNA fragments obtained for particular strains were give in Table 2, while their numbers - in Table 3.

The results showed, that in case of primers from OPA03 to OPA05 and OPA09 all fragments of DNA obtained from analyzed strains were fully monomorphic (they occurred in all cultures of the analyzed strain). This suggested a lack of genetic variability of analyzed strains in respect to above mentioned primers and obtained bands. Low genetic variability occurred in the analysis of the frequency of occurrence of DNA fragments in case of remaining primers, namely OPA01, OPA02 and OPA10. Employing in the amplification procedure the OPA10 primer gave an additional band (1129 nucleotides) for the strains CBS 136.88; this band was monomorphic for all analyzed cultures of that strain (Fig. 6).

In case of the primer OPA01 for Polish strains (HMIPC 16136 and HMIPC 16664) we obtained 6 and 7 bands, respectively; four of them were monomorphic. For the strains from CBS Utrecht (CBS 354.76 and CBS 136.88) we obtained only 4 fragments of DNA, the lengths of which matched the lengths of bands for monomorphic strains from Poland. The primer OPA02 gave in total 9 fragments of DNA. Two facts need special attention: first, the fragment of the length of 934 nucleotides occurred only in the

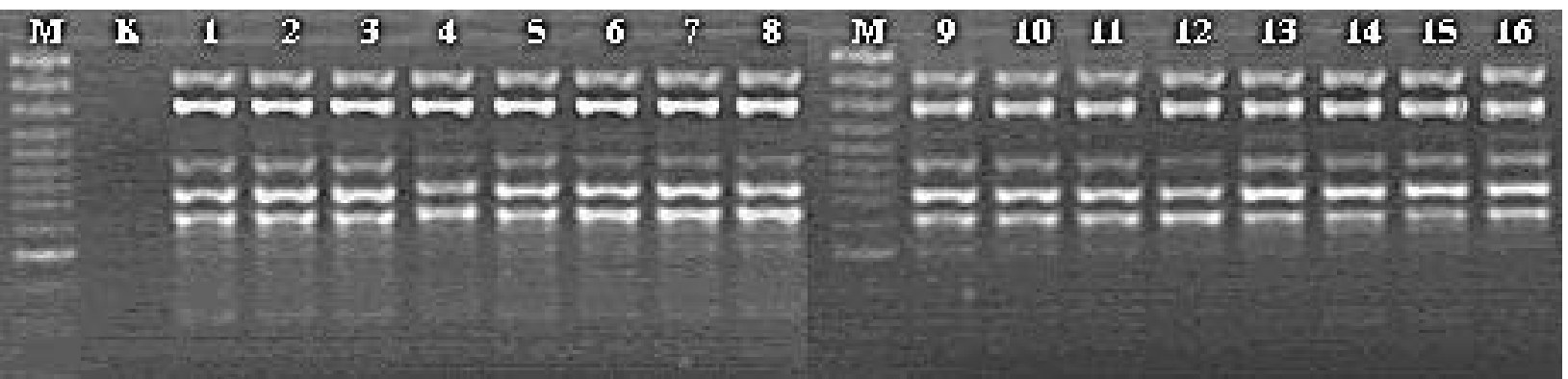

Fig. 5. Pattern of bands obtained as a result of amplification of DNA in four strains of Chalara ovoidea employing the primer OPA04 (Operon). Lines: M marker, K - control (without DNA), lines 1 - 4 strain HMIPC 16136, lines 5 - 8 strain HMIPC 16664, lines 9 - 12 strain CBS 354.76 , lines 13 - 16 strain CBS 136.88 .

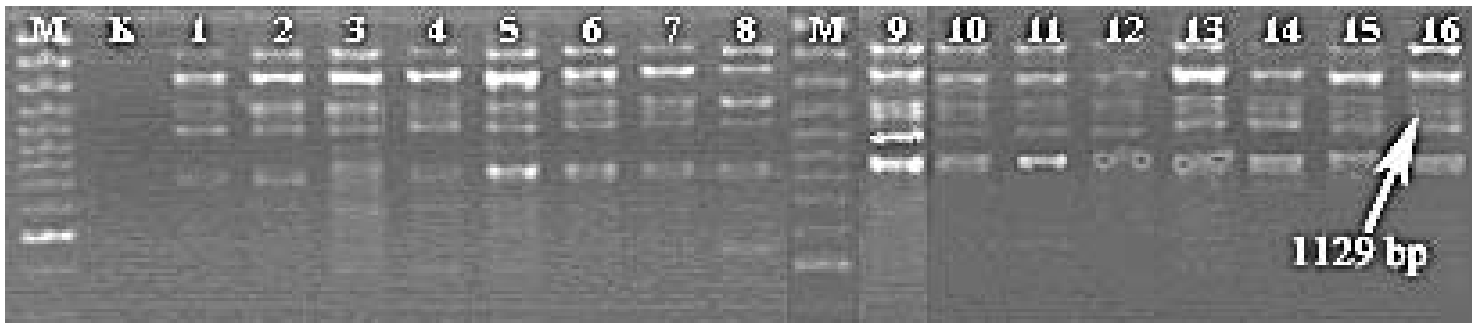

Fig. 6. Pattern of bands obtained as a result of amplification of DNA in four strains of Chalara ovoidea employing the primer OPA10 (Operon). Lines: M marker, K - control (without DNA), lines 1 - 4 strain HMIPC 16136, lines 5 - 8 strain HMIPC 16664, lines 9 - 12 strain CBS 354.76 , lines 13 - 16 strain CBS 136.88. 
TABLE 3. Number of obtained DNA fragments for particular strains of Chalara ovoidea.

\begin{tabular}{|c|c|c|c|c|c|c|c|c|}
\hline \multirow{3}{*}{ Primer } & \multicolumn{8}{|c|}{ Strains } \\
\hline & \multicolumn{2}{|c|}{ HMIPC 16136} & \multicolumn{2}{|c|}{ HMIPC 16664} & \multicolumn{2}{|c|}{ CBS 354.76} & \multicolumn{2}{|c|}{ CBS 136.88} \\
\hline & $\begin{array}{c}\text { all } \\
\text { fragments }\end{array}$ & $\begin{array}{l}\text { monomorphic } \\
\text { fragments }\end{array}$ & $\begin{array}{c}\text { all } \\
\text { fragments }\end{array}$ & $\begin{array}{l}\text { monomorphic } \\
\text { fragments }\end{array}$ & $\begin{array}{c}\text { all } \\
\text { fragments }\end{array}$ & $\begin{array}{l}\text { monomorphic } \\
\text { fragments }\end{array}$ & $\begin{array}{c}\text { all } \\
\text { fragments }\end{array}$ & $\begin{array}{c}\text { monomorphic } \\
\text { fragments }\end{array}$ \\
\hline OPA01 & 6 & 4 & 7 & 4 & 4 & 4 & 4 & 4 \\
\hline OPA02 & 8 & 6 & 9 & 9 & 4 & 4 & 8 & 8 \\
\hline OPA03 & 5 & 5 & 5 & 5 & 5 & 5 & 5 & 5 \\
\hline OPA04 & 5 & 5 & 5 & 5 & 5 & 5 & 5 & 5 \\
\hline OPA05 & 6 & 6 & 6 & 6 & 6 & 6 & 6 & 6 \\
\hline OPA09 & 4 & 4 & 4 & 4 & 4 & 4 & 4 & 4 \\
\hline OPA10 & 5 & 5 & 5 & 5 & 5 & 5 & 6 & 6 \\
\hline
\end{tabular}

TABLE 4. The statistical characteristics of the Chalara ovoidea strains based upon the Jaccard's coefficient of similarity.

\begin{tabular}{|c|c|c|c|c|c|c|}
\hline Strain & $\begin{array}{c}\text { Mean Jaccard's } \\
\text { coefficient }\end{array}$ & $\begin{array}{l}\text { Standard } \\
\text { deviation }\end{array}$ & $\begin{array}{l}\text { Coefficient } \\
\text { of variability }\end{array}$ & Maximum & Minimum & Range \\
\hline HMIPC 16136 & 0.919 & 0.042 & 0.045 & 1.0 & 0.846 & 0.154 \\
\hline HMIPC 16664 & 0.915 & 0.054 & 0.059 & 1.0 & 0.805 & 0.195 \\
\hline CBS 354.76 & 0.901 & 0.064 & 0.071 & 1.0 & 0.805 & 0.195 \\
\hline CBS 136.88 & 0.922 & 0.052 & 0.056 & 1.0 & 0.868 & 0.132 \\
\hline
\end{tabular}

TABLE 5. Matrix of genetic distances among the strains of Chalara ovoidea.

\begin{tabular}{lccc}
\hline \multirow{2}{*}{ Strain } & \multicolumn{2}{c}{ Mean Jaccard's coefficient for the strain } \\
\cline { 2 - 4 } & HMIPC 16136 & HMIPC 16664 CBS 354.76 \\
\hline HMIPC 16136 & 1.0 & & 1.0 \\
HMIPC 16664 & 0.9249 & 0.8414 & 1.0 \\
CBS 354.76 & 0.8932 & 0.9199 & 0.8684 \\
CBS 136.88 & 0.8990 & 1.0 \\
\hline
\end{tabular}

strain HMIPC 16664, and was monomorphic for that population. Because we did not find this fragment in the strain HMIPC 16136, it could be used for telling apart the Polish strains after conducting other investigations. Secondly, for the strains CBS 354.76 and CBS 136.88 the primer OPA02 gave 4 and 8 fragments of DNA, respectively. All these DNA fragments were monomorphic within a strain (Table 3). In case of the strain CBS 354.76 there were 4 DNA fragments missing; their respective lengths were 2513,
1939, 934 and 561 nucleotides. Also the mentioned above band with 1129 nucleotides, being a result of amplification using primer OPA10, did not occur in that strain.

Calculating the Jaccard's coefficient of similarity for the pairs of cultures allowed for a closer statistical description of the investigated populations. Data presented in Table 4 indicated, that the most similar are the Polish strains (HMIPC 16136 and HMIPC 16664) and the strain CBS 136.88, while the most distant one was the strain CBS

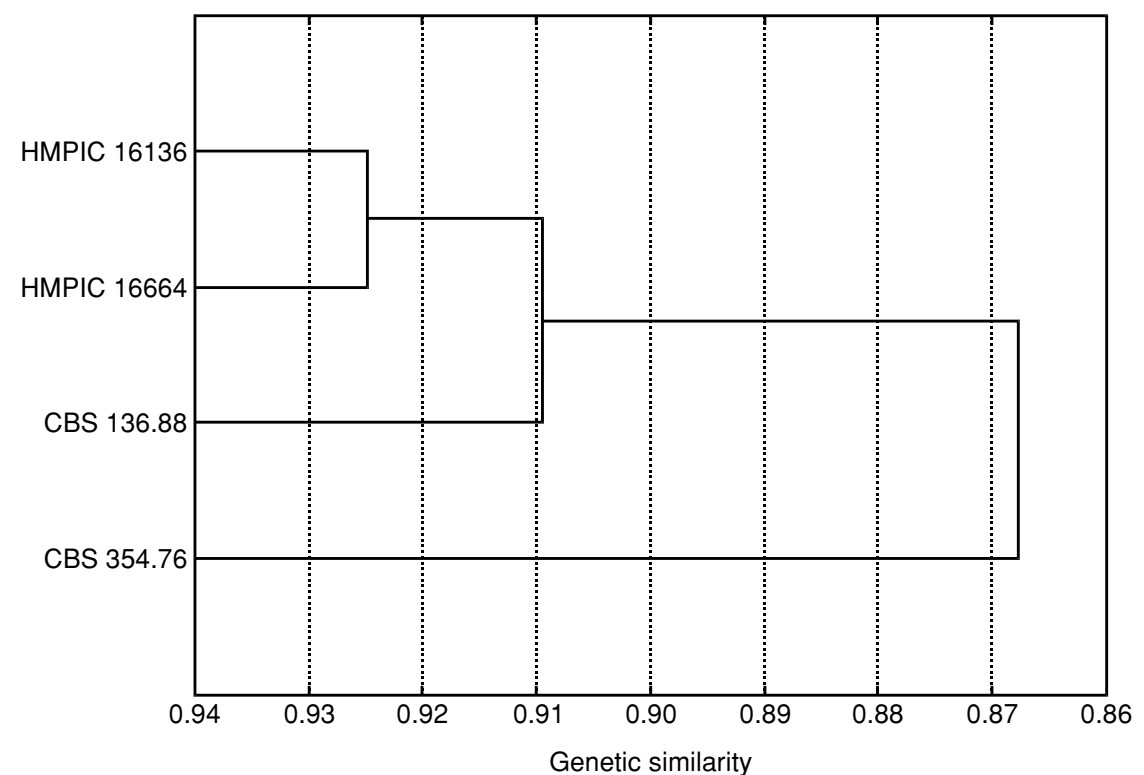

Fig. 7. A dendrogram for 4 strains of Chalara ovoidea obtained by unweighted pair group average (UPGMA) method. The genetic similarity calculated using the Jaccard's formula. 
354.76. Certainly that was caused by the fact, that this strain lacked the above mentioned DNA fragments, which were produced during the amplification procedure with the primers OPA02 and OPA10. The presented above relationships based upon the genetic distance between strains were supported by the matrix of genetic similarity (Table 5) and by the dendrogram constructed on the basis of data contained in that matrix (Fig. 7).

Using the Mantel matrix-correspondence test we estimated the accuracy, with which the dendrogram represents the genetic similarity among the analyzed strains of Chalara. The coefficient of correlation (r) was 0.78 , which indicated an appropriate grouping of analyzed strains.

\section{DISCUSSION}

The results prove the usefulness of the RAPD markers for examining the taxonomic identity of the analyzed strains of Chalara ovoidea. Using the Jaccard's coefficient we showed, that the Polish strains of Chalara were genetically very similar to the strains from CBS Utrecht (Table 3,4). The genetic likeness among Polish strains (HMIPC 16136 and HMIPC 16664) was higher than the likeness among the strains (CBS 354.76 i CBS 136.88) which were used as a standard in our investigations; the Jaccard's coefficient of similarity was 0.92 and 0.87 , respectively. There were also ascertained some differences in morphological features and in production of spores among the analyzed strains. The strain CBS 354.76, which had smaller endoconidia and aleuroconidia than in other strains, was also characterized by the lack of bands $(2513,1939,934,561 \mathrm{bp})$ in the electrophoretic gel. These bands occurred in all other analyzed strains of Chalara.

The recent research based upon the nuclear DNA sequences showed, that Chalara according to the contemporary taxonomic approach is an polyphyletic genus (Paulin and Harrington 2000). On the basis of parsimony analysis of the sequences obtained from a large sub-unit (LSU) and internal transcribed spacer regions (ITS) rDNA Paulin-Mahady et al. (2002) suggested, that the species of the genus Chalara, which displayed Ceratocystis affinities, should be included into the genus Thielaviopsis. The new nomenclature combination for the species analyzed in this paper should be Thielaviopsis ovoidea (Nag Raj et Kendrick) Paulin, Harrington et McNew. In this paper we still used the name Chalara ovoidea, as it was used also in the original description of the species (Nag Raj and Kendrick 1975).

It is essential to note, that the analysis of rDNA sequence presented in the paper by Paulin-Mahady et al. (2002) did not allow to find any differences between the strains CBS 354.76 and CBS 136.88 of Chalara ovoidea. These had been exactly the same strains, which were analyzed in our work using RAPD method on genomic DNA. The reason for not finding differences by Paulin-Mahady et al. (2002) could be the use of ribosomal DNA, which is commonly used as a tool in taxonomy (to identify the species) and in phylogenetic investigations (Henrion et al. 1994; Lovic et al. 1995).

The morphological and genetical analyses showed, that the strains isolated in Poland belonged to Chalara ovoidea. This was the first well documented case of finding that species in Poland. This refers both to the strains isolated from beech planks with the signs of gray-brown discoloration, and to the wood in necroses found in the stems of live specimens of Fagus sylvatica. This is a good starting point for further research on the teleomorph of Chalara ovoidea, which is still not known to science (Nag Raj and Kendrick 1975).

Our research confirmed the need to optimize the concentration of the Magnesium ions in the reaction mixture. Obtaining visible and clear bands in electrophoretic gels while analyzing the genetic affinity using RAPD method needs an optimization of the conditions in which the PCR reaction is conducted. It refers especially to the choice of proper concentrations of the magnesium ions in the reaction mixture, which could be different depending upon the kind of primer used in the reaction, the kind of polymerase (producer) and the species under study (Bousquet et al. 1990; Carlson et al. 1991; Kraj 2002).

Our research showed, that for each primer which starts a positive PCR reaction we can match such a concentration of Magnesium ions, which allows for an easy identification of bands characteristic for each species of fungus. The problem of optimizing the concentration of Magnesium ions in the reaction mixture has been discussed by numerous authors. Bosquet at al. (1990) wrote, that choosing right concentrations of $\mathrm{Mg}^{++}$ions permits minimizing the errors caused by the Taq DNA polymerase during the PCR reaction, thus increasing the repeatability of analyses. The optimization of the concentration of Magnesium ions was conducted by Carlson et al. (1991) for Picea glauca Voss. They concluded, that in case of too high concentration of Magnesium ions a diffuse band is produced, being an effect of producing during the PCR reaction some non-specific DNA fragments of very similar lengths; low variability in length of these DNA fragments makes their electrophoretic separation virtually impossible, so no discrete bands are produced.

Too low concentration of $\mathrm{Mg}^{++}$leads to production of a low number of bands, which are usually hardly visible. In both cases determining the actual genetic variability of analyzed individuals is quite difficult. Also other authors mentioned the need of optimizing the concentration of Magnesium ions before conducting the main analyses. For example, Devos and Gale (1992) conducted such investigations on wheat Triticum aestivum L., Barcaccia (1994) conducted it on Medicago sativa L. All above mentioned authors suggested, that the right concentration of Magnesium ions is a prerequisite for obtaining clear and interpretable electrophoretic pictures.

\section{LITERATURE CITED}

BARCACCIA G. 1994. Development - comparability and potential applications of RAPD [Random Amplified Polymorphic DNAs] markers in the genus Medicago. J. Genet. Breed. 48, 2: 161-168.

BOUSQUET J., SIMON L., LALONDE M. 1990. DNA amplification from vegetative and sexual tissues of trees using polymerase chain reaction. Can. J. For. Res. 20: 254-257.

CARLSON J.E., TULSIERAM L.K., GLAUBITZ J.C., LUK V.M.K., KAUFFELDT C., RUTLEDGE R. 1991. Segregation of random amplified DNA markers in $\mathrm{F} 1$ progeny of conifers. Theor. Appl. Genet. 83, 2: 194-200. 
DEVOS K.M., GALE M.D. 1992. The use of random amplified polymorphic DNA markers in wheat. Theor. Appl. Genet. 84, 5-6: 567-572.

GOWER J.C. 1985. Measures of similarity, dissimilarity and distance. In: Encyclopedia of Statistical Sciences, (ed. S. Klotz and N.L. Johnson). Wiley, New York, 397-405.

HENRION B., CHEVALIER G., MARTIN F. 1994. Typing truffle by PCR amplification of the ribosomal DNA spacer. Mycol. Res. 98: 37-43.

JACKSON D.A., SOMERS K.M., HARVEY H.H. 1989. Similarity coefficients: measures of co-occurrence and association or simply measures of occurrence? Am. Nat. 133: 436-453.

KRAJ W. 2002. The estimation of genetic variation within and between polish provenances of Norway spruce (Picea abies (L.) Karst.) on the basis of RAPD polymorphism. EJPAU Series forestry 5, 2: $13 \mathrm{p}$.

LOVIC B.R., MARTY R.D., MILLER M.E. 1995. Sequence analysis of the ITS region of rDNA in Monosporascus spp. to eva- luate its potential for PCR-mediated detection. Phytopathology 85: 655-661.

MANTEL N. 1967. The detection of disease clustering and a generalized regression approach. Cancer Research 27: 209-220.

NAG RAJ T. R., KENDRICK W.B. 1975. A monograph of Chalara and allied genera. University Press, Waterloo, Ontario, Wilfrid Laurier.

PAULIN A.E., HARRINGTON T.C. 2000. Phylogenetic placement of anamorphic species of Chalara among Ceratocystis and other ascomycetes. Stud. Mycol. 45: 169-186.

PAULIN-MAHADY A.E., HARRINGTON T.C., MCNEW D. 2002. Phylogenetic and taxonomic evaluation of Chalara, Chalaropsis, and Thielaviopsis anamorphs associated with $\mathrm{Ce}$ ratocystis. Mycologia. 94, 1: 62-72.

WILLIAMS J.G.K., KUBELIK A.R., LIVAK K.J., RAFALSKI J.A., TINGEY S.V. 1990. DNA polymorphisms amplified by arbitrary primers are useful as genetic markers. Nucleic Acids Res. 18, 22: 6531-6535. 